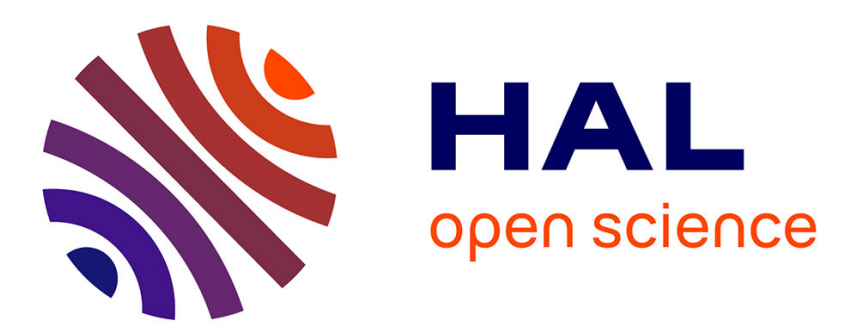

\title{
Multivariable decoupled longitudinal and lateral vehicle control: A model-free design
}

Lghani Menhour, Brigitte d'Andréa-Novel, Michel Fliess, Hugues Mounier

\section{To cite this version:}

Lghani Menhour, Brigitte d'Andréa-Novel, Michel Fliess, Hugues Mounier. Multivariable decoupled longitudinal and lateral vehicle control: A model-free design. 52nd IEEE Conference on Decision and Control CDC 2013, Dec 2013, Florence, Italy. pp.CD-ROM, 10.1109/cdc.2013.6760313 . hal00859444

HAL Id: hal-00859444

https://hal-polytechnique.archives-ouvertes.fr/hal-00859444

Submitted on 9 Sep 2013

HAL is a multi-disciplinary open access archive for the deposit and dissemination of scientific research documents, whether they are published or not. The documents may come from teaching and research institutions in France or abroad, or from public or private research centers.
L'archive ouverte pluridisciplinaire HAL, est destinée au dépôt et à la diffusion de documents scientifiques de niveau recherche, publiés ou non, émanant des établissements d'enseignement et de recherche français ou étrangers, des laboratoires publics ou privés. 


\title{
Multivariable decoupled longitudinal and lateral vehicle control: A model-free design
}

\author{
Lghani MENHOUR $^{\mathrm{a}}$, Brigitte d'ANDRÉA-NOVEL ${ }^{\mathrm{b}}$, Michel FLIESS $^{\mathrm{c}, \mathrm{d}}$ and Hugues MOUNIER ${ }^{\mathrm{e}}$
}

\begin{abstract}
The newly introduced model-free control is applied to a multivariable decoupled longitudinal and lateral vehicle control. It combines two outputs (lateral and longitudinal motions) via two inputs (braking/traction wheel torques and steering angle). It yields driving maneuvers requiring a control coordination of steering angle, braking and traction torques, in order to ensure an accurate tracking in straight or curved trajectories. It is also robust with respect to modeling errors and parametric uncertainties, even during critical driving situations, where such a control is required. Convincing computer simulations are displayed with noisy real data from a laboratory vehicle, which were used as reference trajectories and acquired under high lateral accelerations.
\end{abstract}

Keywords-Intelligent transportation systems, decoupled longitudinal/lateral vehicle control, model-free control, intelligent proportional-integral controllers, flatness-based control.

\section{INTRODUCTION}

The longitudinal or lateral vehicle control problem has been treated in several ways and in many publications (see, for example, [2], [4], [12], [18], [21], [23], and the references therein). Longitudinal and lateral control moreover were generally treated separately. A coupled longitudinal and lateral vehicle control based on flatness property and algebraic identification techniques has therefore been recently proposed in [15], [16], [17]. The performance of those vehicle controllers are often satisfactory. Note that all of them require a rather "good" knowledge of the mathematical models. Unfortunately, this requirement is not always satisfied.

The newly introduced model-free control [6], which has already been quite successfully employed in many concrete situations (see the references in [6]), is a most appropriate tool for the regulation of intelligent transportation systems (see [1], [3], [5], [24], [25]), where a poor modeling knowledge is, as already said, almost always unavoidable. Here we are dealing with a MIMO system which reduces thanks to a clear-cut decoupling to two SISO ones. This decoupling

This work was supported by the French national project INOVE/ANR 2010 BLANC 308.

${ }^{a}$ Centre de Recherche STIC, IUT de Troyes, 9, Rue du Québec, 10000 Troyes, France. Ighani.menhoureuniv-reims.fr

${ }^{b}$ Mines-ParisTech, CAOR - Centre de Robotique, Mathématiques et Systèmes, 60 boulevard Saint-Michel, 75272 Paris cedex 06, France.

brigitte.dandrea-novel@mines-paristech. fr

${ }^{c}$ LIX (CNRS, UMR 7161), École polytechnique, 91128 Palaiseau, France. Michel.Fliessapolytechnique.edu

${ }^{\mathrm{d}}$ AL.I.E.N. (ALgèbre pour Identification \& Estimation Numériques), 2430 rue Lionnois, BP 60120, 54003 Nancy, France.

wWw.alien-sas.com

michel.fliess@alien-sas.com

${ }^{e}$ L2S (UMR 8506), CNRS - Supélec - Université Paris-Sud, 3 rue JoliotCurie, 91192 Gif-sur-Yvette, France.

hugues.mounier@lss.supelec.fr exploits the flatness property of the approximate model of [15], [16], [17]. This modeling provides good results with well known nominal values of the cornering stiffnesses $C_{f}$ and $C_{r}$. However, when the numerical values of those parameters are for instance $30 \%$ smaller, the performances in terms of tracking errors deteriorate quite a lot as shown in Figure 1. This is already a good reason for a model-free control design.
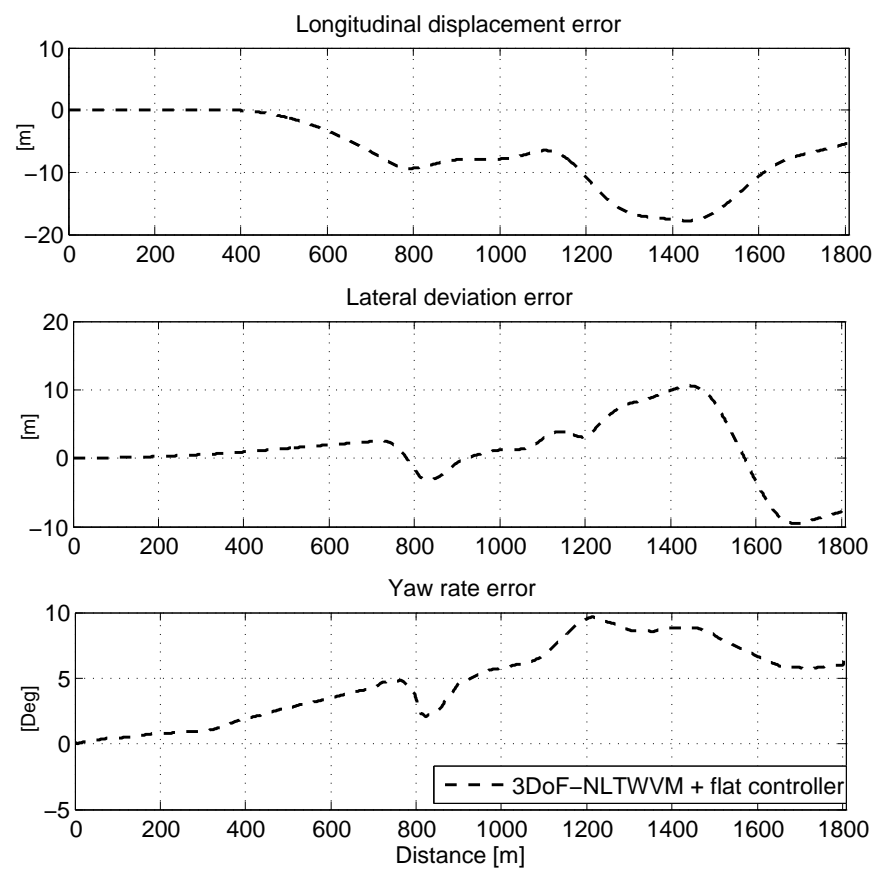

Fig. 1. Trajectories errors of 3DoF-NL2WVM coupled with nonlinear flat longitudinal and lateral vehicle control (see [15] for details.)

The outline of this paper is as follows. The next Section II is devoted to a sketch of model-free control. A short review of the model-based results in [15], [16], [17] is presented in Section III. They are useful not only for simulation purposes, but also to select the appropriate outputs for the model-free setting of Section IV. Computer simulation using real data acquired on a real track race with high dynamic loads are presented in Section V. Section VI not only suggests further studies but also concludes with some general considerations on the model-free design. 


\section{MODEL-FREE CONTROL: A SHORT REVIEW ${ }^{1}$}

\section{A. The model-free control design}

1) The ultra-local model: The unknown global description of the plant is replaced by the ultra-local model

$$
y^{(v)}=F+\alpha u
$$

where

- the derivation order $v \geq 1$ is selected by the practitioner;

- $\alpha \in \mathbb{R}$ is chosen by the practitioner such that $\alpha u$ and $y^{(v)}$ are of the same magnitude.

Remark 2.1: The existing examples show that $v$ may always be chosen quite low, i.e., 1 or 2 . In almost all existing concrete case-studies, $v=1$.

Some comments on $F$ are in order:

- $F$ is estimated via the measure of $u$ and $y$;

- $F$ subsumes not only the unknown structure of the system but any perturbation.

2) Intelligent PIs: Set $v=1$ in Equation (1):

$$
\dot{y}=F+\alpha u
$$

Close the loop via the intelligent proportional-integral controller, or $i P I$,

$$
u=-\frac{F-\dot{y}^{*}+K_{P} e+K_{I} \int e}{\alpha}
$$

where

- $e=y-y^{\star}$ is the tracking error,

- $K_{P}, K_{I}$ are the usual tuning gains.

Combining Equations (2) and (3) yields

$$
\dot{e}+K_{P} e+K_{I} \int e=0
$$

where $F$ does not appear anymore. The tuning of $K_{P}, K_{I}$ is therefore quite straightforward. This is a major benefit when compared to the tuning of "classic" PIs.

Remark 2.2: If $K_{I}=0$ we obtain the intelligent proportional controller, or $i P$,

$$
u=-\frac{F-\dot{y}^{*}+K_{P} e}{\alpha}
$$

\section{B. Estimation of $F$}

$F$ in Equation (1) is assumed to be "well" approximated by a piecewise constant function $F_{\text {est }}$. According to the algebraic parameter identification developed in [9], [10], rewrite, if $v=1$, Equation (2) in the operational domain (see, e.g., [26])

$$
s Y=\frac{\Phi}{s}+\alpha U+y(0)
$$

where $\Phi$ is a constant. We get rid of the initial condition $y(0)$ by multiplying both sides on the left by $\frac{d}{d s}$ :

$$
Y+s \frac{d Y}{d s}=-\frac{\Phi}{s^{2}}+\alpha \frac{d U}{d s}
$$

\footnotetext{
${ }^{1}$ See [6] for details and further explanations.
}

Noise attenuation is achieved by multiplying both sides on the left by $s^{-2}$. It yields in the time domain the realtime estimate

$$
F_{\mathrm{est}}(t)=-\frac{6}{\tau^{3}} \int_{t-\tau}^{t}[(\tau-2 \sigma) y(\sigma)+\alpha \sigma(\tau-\sigma) u(\sigma)] d \sigma
$$

where $\tau>0$ might be quite small. This integral may of course be replaced in practice by a classic digital filter.

Remark 2.3: The above estimation methods are not of asymptotic type. They do not require any statistical knowledge of the corrupting noises.

Remark 2.4: See [11] for the implementation of those new intelligent controllers on cheap and small programmable devices.

\section{Simplified NONLINEAR Vehicle Models}

Two vehicle models (see [15], [16], [17] for details) are used to conduct some simulation tests and control design. They have different levels of complexity. The first one (3DoF-NLTWVM) with two wheels has three degrees of freedom. The second one (10DoF-NLFWVM) with four wheels has ten degrees of freedom..

3DoF-NLTWVM: The first model provides a sufficient approximation of the longitudinal and lateral dynamics of the vehicle. The three degrees of freedom which compose this model are: longitudinal $V_{x}$, lateral $V_{y}$ and yaw $\dot{\psi}$ motions. The equations of this model are:

$$
\left\{\begin{array}{l}
m\left(\dot{V}_{x}-\dot{\psi} V_{y}\right)=F_{x 1}+F_{x 2} \\
m\left(\dot{V}_{y}+\dot{\psi} V_{x}\right)=F_{y 1}+F_{y 2} \\
I_{z} \ddot{\psi}=M_{z 1}+M_{z 2}
\end{array}\right.
$$

It is also used to identify the appropriate flat outputs ${ }^{2}$ in order to design a decoupled longitudinal/lateral control.

10DoF-NLFWVM: The second one presents a high level of complexity and a good behavior of the vehicle even under high lateral acceleration. In fact, the 10DoF-NLFWVM is used as complete vehicle simulator and is composed from: three translational motions (longitudinal $V_{x}$, lateral $V_{y}$ and vertical $V_{z}$ ), three rotational motions (roll $\phi$, pitch $\theta$ and yaw $\phi$ ) and dynamical models of four wheels. The different forces of NLFWM are computed using a coupled nonlinear tire model of Pacejka [20] in order to simulate the realistic behavior of vehicle. In fact, this model takes into account the coupling of vertical, longitudinal and lateral motions.

Remark 3.1: The vehicle models presented here are used not only for simulations, but also to give an idea to the reader of the physical significance of the system variables.

Remark 3.2: Let us remind that the techniques of [7] were employed for estimations and identifications related to the above approximate modeling.

\footnotetext{
${ }^{2}$ See [8], and [14], [22], for an introduction to differentially flat systems and to their control.
} 
TABLE I

NOTATIONS

\begin{tabular}{l|l} 
Symbol & Variable name \\
$V_{x}, V_{y}$ & longitudinal and lateral speeds $[\mathrm{m} / \mathrm{s}]$ \\
$\dot{\psi}, \psi$ & yaw rate $[\mathrm{rad} / \mathrm{s}]$, yaw angle $[\mathrm{rad}]$ \\
$u_{1}=T_{\omega}$ & wheel torque $[\mathrm{Nm}]$ \\
$u_{2}=\delta$ & wheel steer angle $[\mathrm{deg}]$ \\
$F_{x i}$ & longitudinal forces in the vehicle coordinate $[\mathrm{N}]$ \\
$F_{y i}$ & lateral forces in the vehicle coordinate $[\mathrm{N}]$, \\
$M_{z i}$ & yaw moment $[\mathrm{Nm}]$ \\
$L_{f}, L_{r}$ & distances from the CoG to the front and rear axles $[\mathrm{m}]$ \\
$I_{z}$ & yaw moment of inertia $\left[\mathrm{Kg}^{-2}\right]$ \\
$g, m$ & acceleration due to gravity $\left[\mathrm{m} / \mathrm{s}^{2}\right]$, vehicle mass $\left[\mathrm{kgm}^{2}\right]$
\end{tabular}

IV. Multivariable DeCoupled longitudinal AND LATERAL VEHICLE CONTROL: A MODEL-FREE SETTING

Our aim is to design a decoupled multivariable longitudinal and lateral vehicle model-free control. The control inputs used to implement this control law are:

- the braking and traction wheel torques to control longitudinal motion,

- the steering angle for lateral and yaw motions.

Consequently, the choice of the appropriate outputs is an important step in order to guarantee an accurate tracking trajectory. Generally, the longitudinal speed $V_{x}$ is used as output to control the longitudinal motion, while for the stability studies of the lateral and yaw motions, the yaw rate $\dot{\psi}$ is used as an output. However, an accurate tracking trajectory cannot be guaranteed only by the yaw rate output, especially if the trajectories are characterized by dangerous bends. Moreover, the yaw rate is used for the lateral stability analysis. In fact, the results obtained with a longitudinal and lateral vehicle model-free control using $y_{1}=V_{x}$ and $y_{2}=\dot{\psi}$ are not satisfactory in terms of trajectory tracking (see Figure 2).

Thus in order to improve the performance of the control law in terms of trajectory tracking, the second output should be function of both yaw and lateral motions (for example the yaw rate $\psi$ and the lateral speed $V_{y}$ ). Consequently, the outputs used previously in [15] can be considered here. These outputs, which have been shown to be flat outputs of system (III), are

$$
\left\{\begin{array}{l}
y_{1}=V_{x} \\
y_{2}=L_{f} m V_{y}-I_{z} \dot{\psi}
\end{array}\right.
$$

Remark 4.1: The second flat output $y_{2}$ represents the angular momentum of a point on the axis between the centers of the front and rear axles.

As already mentioned, the design of a multivariable model-free vehicle control becomes an interesting task to track the desired longitudinal $y_{1}$ and lateral $y_{2}$ outputs. This control approach is implemented via braking and traction wheel torques $u_{1}=T_{\omega}$ and steering angle $u_{2}=\delta$ control inputs. From [15, Equation (12)], the following two subultra-local models of longitudinal and lateral motions can be deduced, in accordance with Equation (2),

$$
\begin{aligned}
\text { longitudinal ultra-local model: } & \dot{y}_{1}=F_{1}+\alpha_{1} u_{1} \\
\text { lateral ultra-local model: } & \dot{y}_{2}=F_{2}+\alpha_{2} u_{2}
\end{aligned}
$$
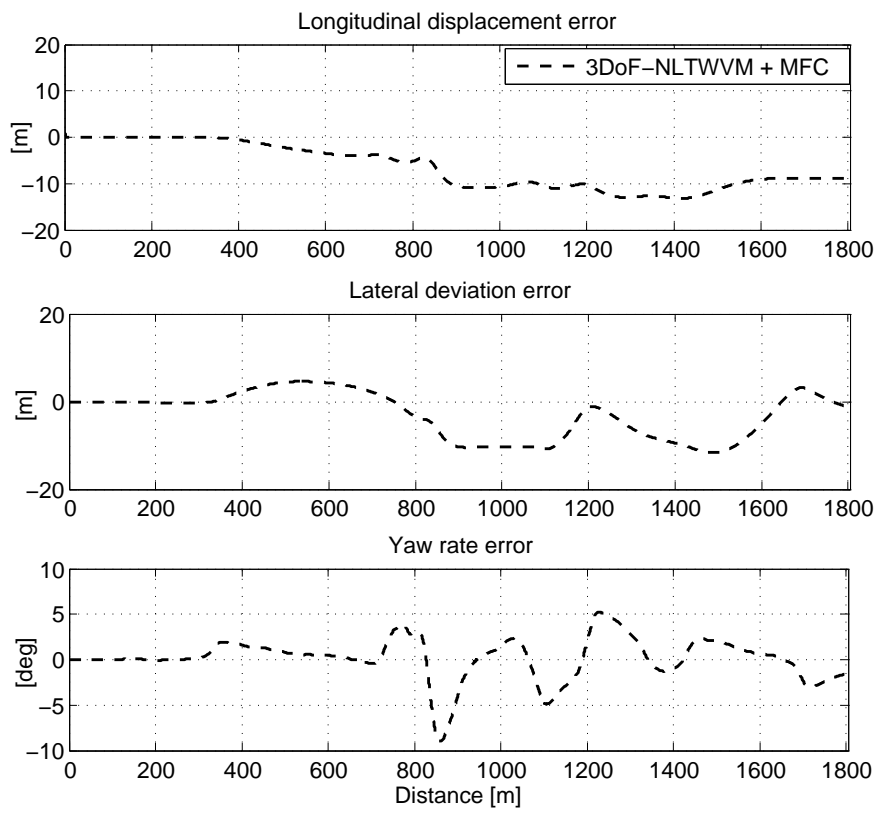

Fig. 2. Trajectories errors of 3DoF-NL2WVM coupled with model-free control and 10DoF-NLFWVM coupled with model-free control using $y_{1}=$ $V_{x}$ and $y_{2}=\dot{\psi}$ as controlled outputs

$u_{1}$ and $u_{2}$ represent respectively the wheel torque control of longitudinal motion $y_{1}$ and the steering angle control of lateral and yaw motions $y_{2}$. The tracking is achieved by two decoupled multivariable iPIs. Set, according to Equation (3), for the longitudinal iPI controller $u_{1}=\frac{1}{\alpha_{1}}\left(F_{1}+\dot{y}_{1}^{d}-K_{P}^{y_{1}} e_{y_{1}}-K_{I}^{y_{1}} \int e_{y_{1}} d t\right)$, and for the lateral iPI controller $u_{2}=\frac{1}{\alpha_{2}}\left(F_{2}+\dot{y}_{2}^{d}-K_{P}^{y_{2}} e_{y_{2}}-K_{I}^{y_{2}} \int e_{y_{2}} d t\right)$, where $e_{y_{1}}=y_{1}^{d}-y_{1}=V_{x}^{d}-V_{x}$ and $e_{y_{2}}=y_{2}^{d}-y_{2}$. The choice of the parameters $\alpha_{1}, \alpha_{2}, K_{P}^{y_{1}}, K_{I}^{y_{1}}, K_{P}^{y_{2}}$ and $K_{I}^{y_{2}}$ is straightforward. Equation (4) yields the estimation of $F_{1}$ and $F_{2}$.

\section{COMPARISON WITH EXPERIMENTAL TESTS}

The validation of the proposed control law is performed under high dynamic loads using real data which were acquired via a laboratory vehicle. These data were obtained during several trails in presence of a decoupled longitudinal/lateral behaviors. A set of dynamic parameters has been acquired such as yaw and roll rates, lateral and longitudinal accelerations, wheel rotation speeds, longitudinal and lateral speeds, longitudinal, lateral and vertical forces on the four wheels, steering angle, steering torque, etc. For these tests the acquisition device operates at a frequency equal to $400 \mathrm{~Hz}$.

For our study, the experimental data are used as reference signals to perform simulation in closed-loop of control laws coupled with vehicle models. The obtained results are compared to the measurements. In fact, the model-free control approach is tested using several trials data performed on a race track with a laboratory vehicle (the trajectory $\mathrm{X}-\mathrm{Y}$ of the race track is presented in Figure 7). Other dynamical parameters of this test are shown in Figures $3-7$. This test presents a coupled longitudinal/lateral maneuver performed 

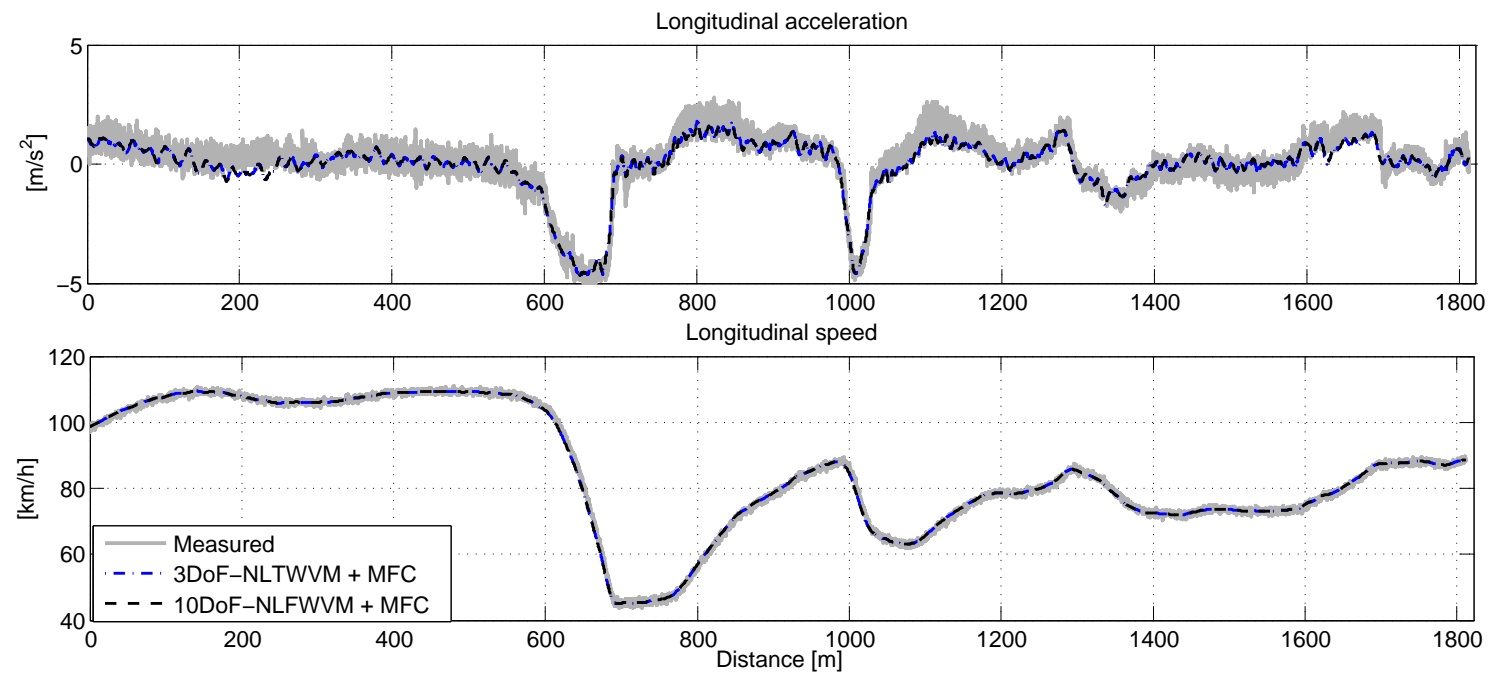

Fig. 3. Longitudinal acceleration and longitudinal speed: Measured, those of 3DoF-NL2WVM coupled with model-free control and 10DoF-NLFWVM coupled with model-free control
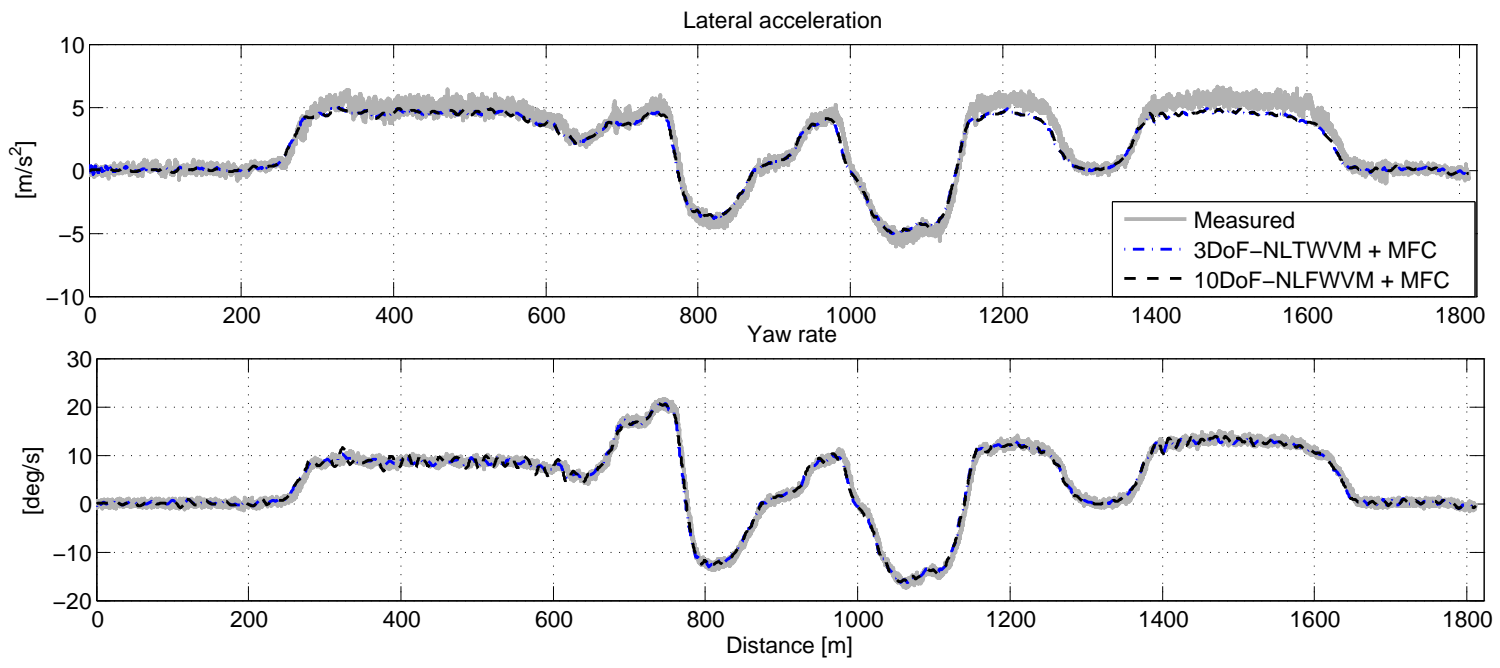

Fig. 4. Lateral acceleration and yaw rate: Measured, those of 3DoF-NL2WVM coupled with model-free control and 10DoF-NLFWVM coupled with model-free control

under high lateral accelerations as shown in Figure 4 (lateral acceleration $-5 \mathrm{~m} / \mathrm{s}^{2} \leqslant a_{y} \leqslant 5 \mathrm{~m} / \mathrm{s}^{2}$ ).

Figures 3 and 4 show the longitudinal and lateral motions of the two controlled vehicle models (3DoF-NLTWVM and 10DoF-NLFWVM). The obtained behavior with this simulation is close to measured ones like yaw rate, longitudinal speed, longitudinal and lateral accelerations. We can observe also the performance of the control law in terms of trajectory tracking, the controlled models providing a realistic trajectory (see Figure 7). Indeed, the tracking errors on longitudinal displacement, lateral deviation and yaw angle, which are depicted in Figure 5, are quite small and satisfactory whatever the dynamic loads, the nature of the trajectory and the two vehicle models used.

The model-free control is able to provide a realistic behavior in terms of steering angle and braking/traction wheel torque. This behavior is similar to the measured ones, for any given vehicle model (3DoF or 10DoF) as shown in Figure 6, especially during the sharp braking and steering maneuvers performed between the positions from $600 \mathrm{~m}$ to $750 \mathrm{~m}$ and from $1000 \mathrm{~m}$ to $1080 \mathrm{~m}$, as illustrated in Figure 6. During these two driving steps, as mentioned on Figures 3 and 4, the combined steering and braking maneuvers are performed simultaneously in the most dangerous bends as illustrated in Figure 7.

The stability region of the sideslip motion of the vehicle is shown by Figure 8 according to [13], [19]. The controlled vehicle model operates inside the stability region, however, the uncontrolled model operates outside the stability region. Notice that the unstability of the uncontrolled vehicle model is produced between the positions $600 \mathrm{~m}$ and $750 \mathrm{~m}$. During this phase, the vehicle is subjected to coupled steering and sharp braking maneuvers. These results confirm the ability of the proposed model-free control to maintain a good stability 

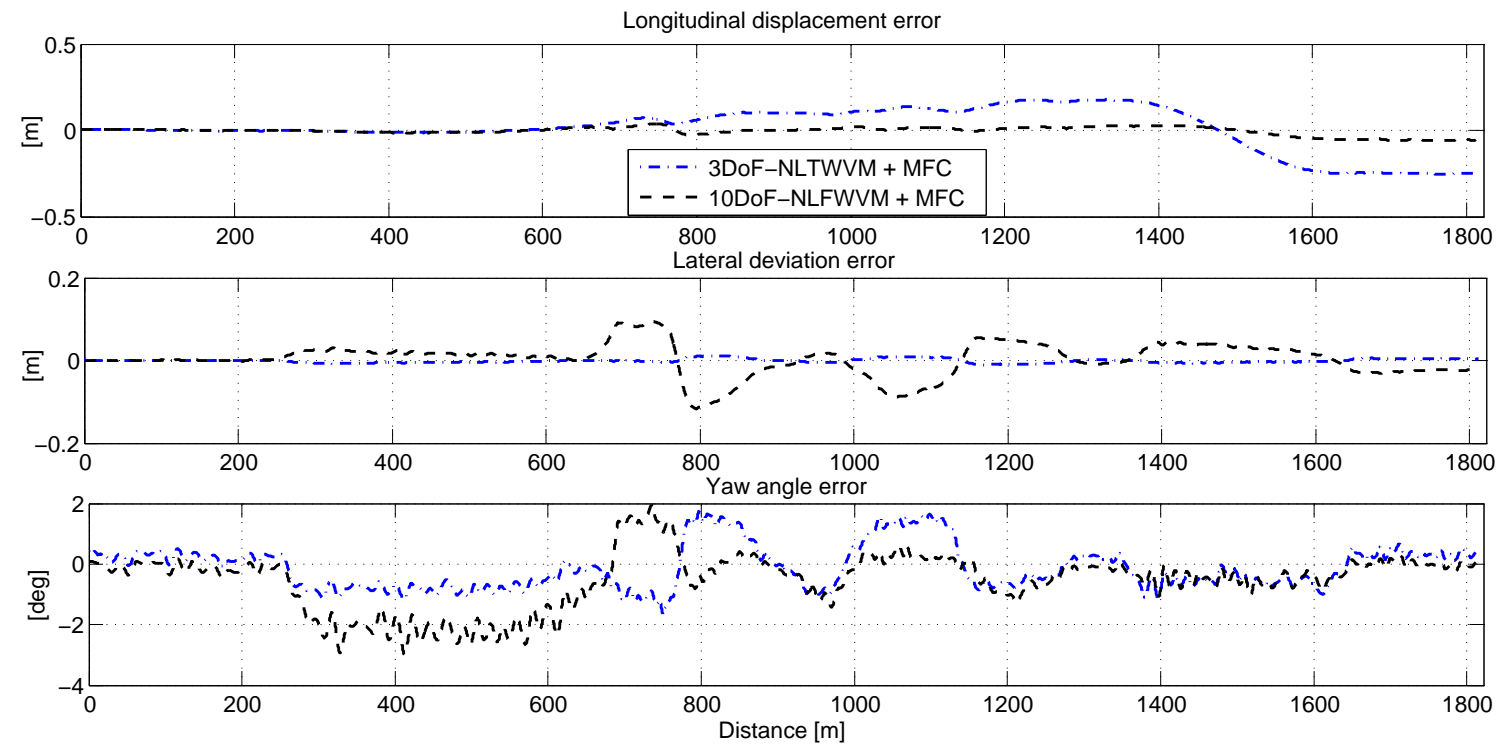

Fig. 5. Tacking trajectory errors on longitudinal displacement, lateral deviation and yaw angle of 3DoF-NL2WVM coupled with model-free control and 10DoF-NLFWVM coupled with model-free control
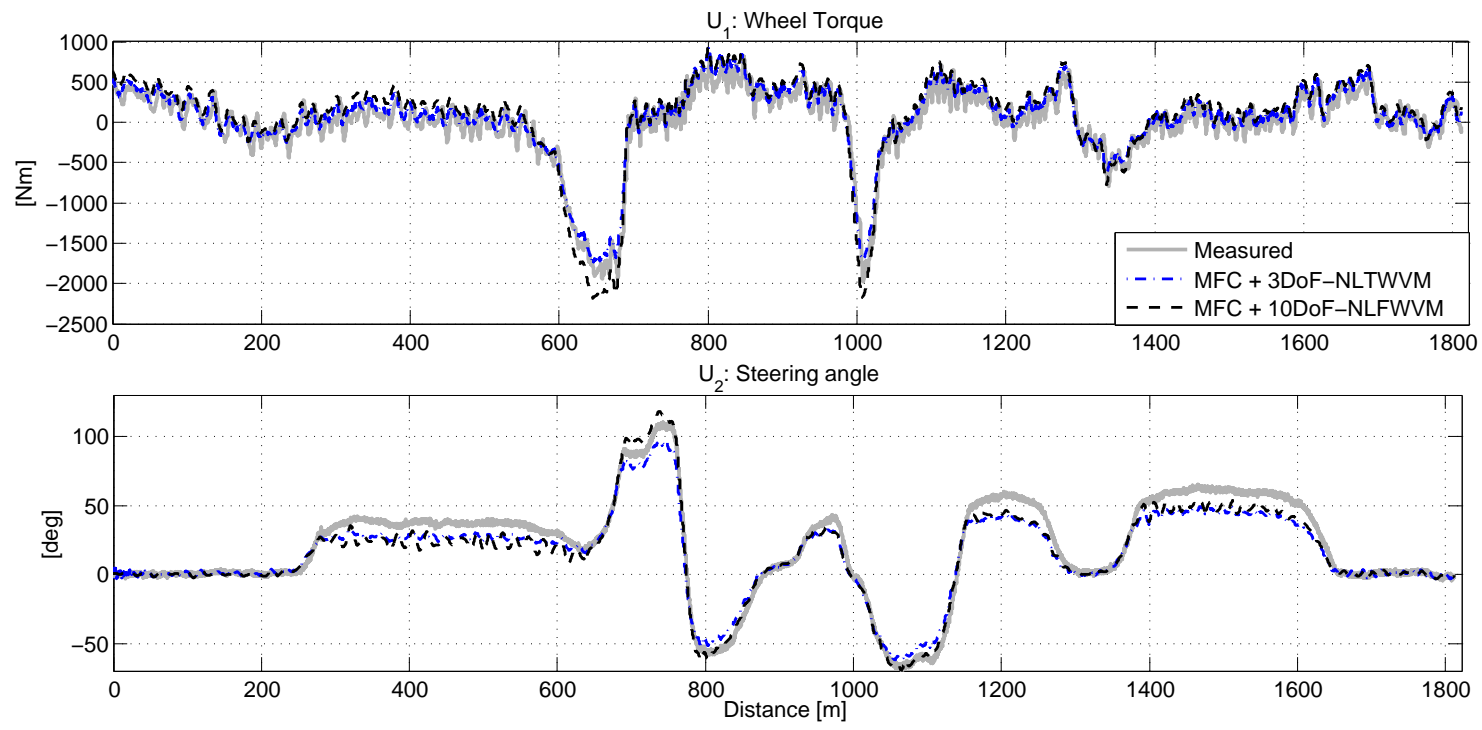

Fig. 6. Wheel torques and steering angles control signals: measured and those obtained with model-free control coupled with two vehicle models (3DoF-NL2WVM and 10DoF-NLFWVM)

of the vehicle model.

A realistic behavior is thus obtained for the tracking trajectory, when the control law is tested with a realistic vehicle simulator (10DoF-NLFWVM) and in the presence of coupled braking/traction and steering maneuvers. The ability and the effectiveness of a model-free control to operate under extreme and coupled nonlinear vehicle behaviors (for lateral acceleration $-5 \mathrm{~m} / \mathrm{s}^{2} \leqslant a_{y} \leqslant 5 \mathrm{~m} / \mathrm{s}^{2}$ ) is therefore confirmed.

\section{CONCLUSION}

The possible need of a "good" but "complex" approximate mathematical modeling for computer simulations purposes was already pointed out in [1] and [6], although the modelfree control design might be rather straightforward. Here the approximate mathematical modeling is also useful because

1) the flatness property leads to a better choice of the output variables in the model-free ultra-local model;

2) the two flat outputs are related to a "natural" decoupling which permits to greatly simplify the mathematics of the model-free setting.

Those two points, which are new in the discussions about the epistemological questions raised by the model-free viewpoint, might therefore be interesting for further studies.

Future works will be devoted to

- other intelligent controllers,

- the search of other suitable outputs for model-free control, 


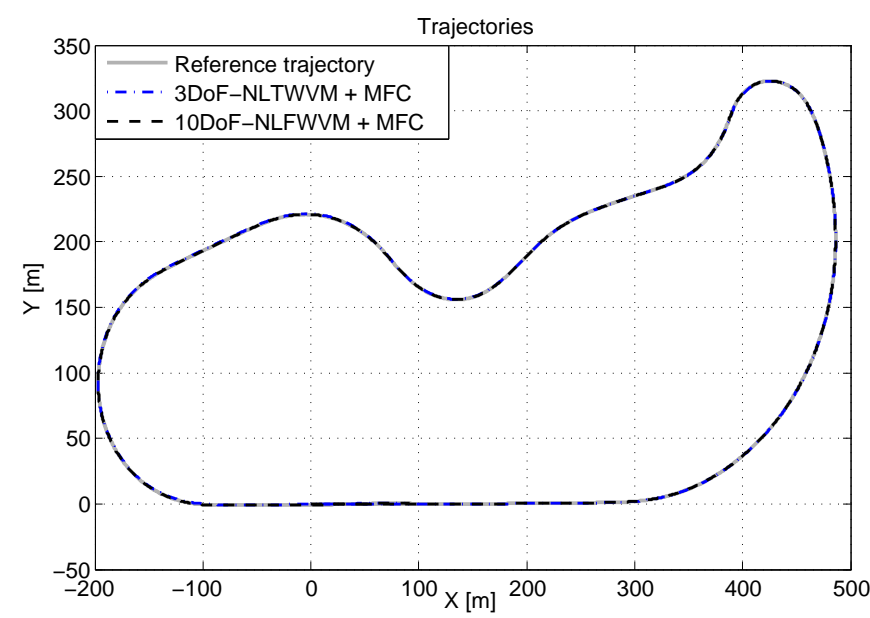

Fig. 7. Trajectories errors of 3DoF-NL2WVM coupled with model-free control and 10DoF-NLFWVM coupled with model-free control

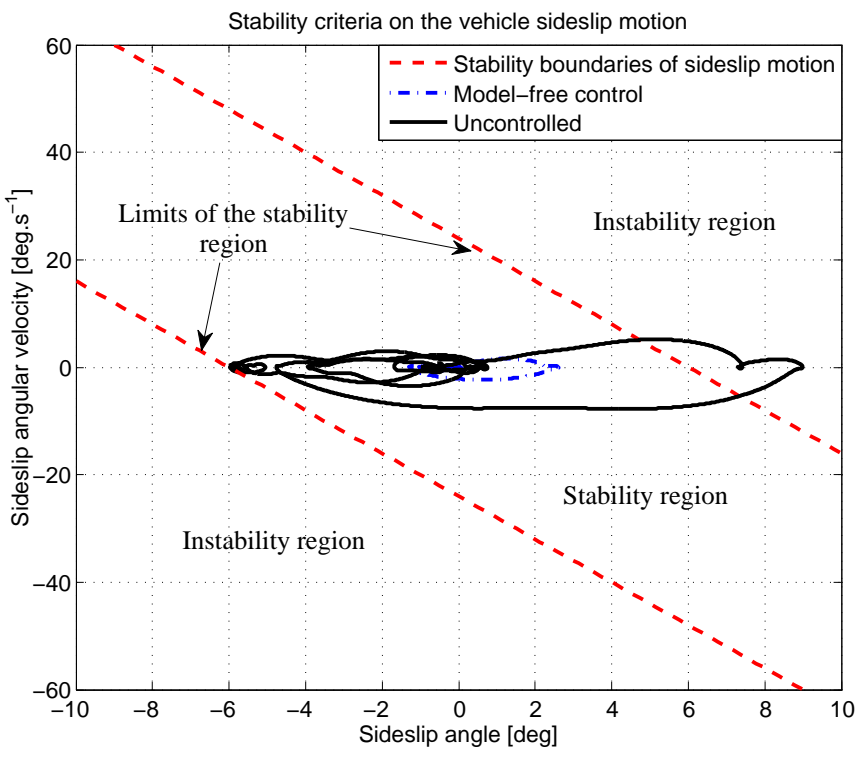

Fig. 8. Stability evolution of the controlled and uncontrolled vehicle models in the $\beta-\dot{\beta}$ plane.

- real experiments, like steering maneuvers combined with stop-and-go control in order to keep a constant distance between the vehicles.

\section{REFERENCES}

[1] H. Abouaïssa, M. Fliess, V. Iordanova, C. Join, "Freeway ramp metering control made easy and efficient", in $13^{\text {th }}$ IFAC Symp. Control Transport. Systems, Sofia, 2012. Preprint available at http://hal.archives-ouvertes.fr/hal-00711847/en/

[2] J. Ackermann, J. Guldner, W. Sienel, R. Steinhauser, V. I. Utkin, "Linear and nonlinear controller design for robust automatic steering", IEEE Trans. Control Syst. Techno., vol. 3, 1995, 112-143.

[3] B. d'Andréa-Novel, C. Boussard, M. Fliess, O. el Hamzaoui, H Mounier, B. Steux, "Commande sans modèle de vitesse longitudinale d'un véhicule électrique", in $\sigma^{e}$ Conf. Internat. Francoph. Automatique, Nancy, 2010. Preprint available at http://hal.archives-ouvertes.fr/inria-00463865/en/

[4] V. Cerone, M. Milanese, D. Regruto, "Combined automatic lanekeeping and driver's steering through a 2-DOF control strategy", IEEE Trans. Control Syst. Techno., vol. 17, 2009, 135-142.
[5] S. Choi, B. d'Andréa-Novel, M. Fliess, H. Mounier, J. Villagra, "Model-free control of automotive engine and brake for Stop-and-Go scenarios", in Europ. Control Conf., Budapest, 2009. Preprint available at http://hal.archives-ouvertes.fr/inria-00395393/en/

[6] M. Fliess, C. Join, "Model-free control", Int. J. Control, 2013, DOI: 10.1080/00207179.2013.810345. Preprint available at http://hal.archives-ouvertes.fr/hal-00828135/en/

[7] M. Fliess, C. Join, H. Sira-Ramírez, "Non-linear estimation is easy", Int. J. Model. Identif. Control, vol. 4, 12-27, 2008. Preprint available at http://hal.archives-ouvertes.fr/inria-00158855/en/

[8] M. Fliess, J. Lévine, P. Martin, P. Rouchon, "Flatness and defect of non-linear systems: introductory theory and examples", Int. J. Control, vol. 61, 1327-1361, 1995.

[9] M. Fliess, H. Sira-Ramírez, "An algebraic framework for linear identification", ESAIM Control Optimiz. Calc. Variat., vol. 9, 151-168, 2003.

[10] M. Fliess, H. Sira-Ramírez, "Closed-loop parametric identification for continuous-time linear systems via new algebraic techniques", in eds. $\mathrm{H}$. Garnier and L. Wang, Identification of Continuous-time Models from Sampled Data, Springer, pp. 362-391, 2008. Preprint available at http://hal.archives-ouvertes/inria-00114958/en/

[11] C. Join, F. Chaxel, M. Fliess, "Intelligent" controllers on cheap and small programmable devices", in $2^{\text {nd }}$ Int. Conf. Control Fault-Tolerant Systems, Nice, 2013. Preprint available at http://hal.archives-ouvertes.fr/hal-00845795/en/

[12] A. Khodayari, A. Ghaffari, S. Ameli, J. Flahatgar, "A historical review on lateral and longitudinal control of autonomous vehicle motions", in IEEE Int. Conf. Mechanical Electrical Techno., Singapore, 2010.

[13] K. Koibuchi, M. Yamamoto, Y. Fukada, S. Inagaki, "Vehicle stability control in limit cornering by active brake", SAE Technical Paper 960487, 1996, DOI:10.4271/960487.

[14] J. Lévine, Analysis and Control of Nonlinear Systems - A Flatnessbased Approach, Springer, 2009.

[15] L. Menhour, B. d'Andréa-Novel, C. Boussard, M. Fliess, H. Mounier "Algebraic nonlinear estimation and flatness-based lateral/longitudinal control for automotive vehicles", in $14^{\text {th }}$ Int. IEEE Conf. ITS, Washington, 2011. Preprint available at http://hal.archives-ouvertes.fr/hal-00611950/en/

[16] L. Menhour, B. d'Andréa-Novel, M. Fliess, H. Mounier, "Commande couplée longitudinale/latérale de véhicules par platitude et estimation algébrique", in $7^{e}$ Conf. Internat. Francoph. Automatique, Grenoble, 2012. Preprint available at http://hal.archives-ouvertes.fr/hal-00686653/en/

[17] L. Menhour, B. d'Andréa-Novel, M. Fliess, H. Mounier, "Coupled nonlinear vehicle control: Flatness-based setting with algebraic estimation techniques", Control Engin. Practice, to appear. Preprint soon available at http://hal.archives-ouvertes.fr/

[18] S.A. Nobe, F.-Y. Wang, "An overview of recent developments in automated lateral and longitudinal vehicle controls", in IEEE Int. Conf. Syst. Man Cyber., Tucson, 2001.

[19] D. Odenthal, T. Bunte, J.Ackerman, "Nonlinear steering and breaking control for vehicle rollover avoidance", in Europ. Control Conf., Karlsruhe, 1999.

[20] H. B. Pacejka, Tire and Vehicle Dynamics, Elsevier, 2005.

[21] C. Poussot-Vassal, O. Sename, L. Dugard, P. Gaspar, Z. Szaboc, J. Bokor, "Attitude and handling improvements through gain-scheduled suspensions and brakes control", Control Engin. Practice, vol. 19, 252-263, 2011.

[22] H. Sira-Ramírez, S. Agrawal, Differentially Flat Systems, Marcel Dekker, 2004

[23] J. Villagra, B. d'Andréa-Novel, S. Choi, M. Fliess, H. Mounier, "Robust stop-and-go control strategy: an algebraic approach for nonlinear estimation and control", Int. J. Vehicle Autonomous Systems, 7, 270291, 2009. Preprint available at http://hal.archives-ouvertes.fr/inria-00419445/en/

[24] J. Villagra, D. Herrero-Pérez, "A comparison of control techniques for robust docking maneuvers for an AVG", IEEE Trans. Control Systems Techno., 20, 1116-1123, 2012.

[25] J. Villagra, V. Milanés, J. Pérez, T. de Pedro, "Control basado en PID inteligentes: aplicación al control de crucero de un vehículo a bajas velocidades", Rev. Iberoamer. Autom. Inform. Indust., 7, 44-52, 2010.

[26] K. Yosida, Operational Calculus (translated from the Japanese), Springer, 1984 